\title{
Alzheimer's Disease and You: Can Alzheimer's Abduct Consciousness?
}

\section{Md. Sahab Uddin*}

Department of Pharmacy, Southeast University, Dhaka, Bangladesh

\section{Editorial}

Alzheimer's disease (AD) is an irretrievable, neurodegenerative disorders characterized by diverse features of diminished consciousness [1]. This degenerative nerve disorder is characterized by ample loss of self. Worldwide currently 35 million people are affected by $\mathrm{AD}$ [2]. Throughout the course of the $\mathrm{AD}$, proteins accumulation occurs in the brain to form pathogenic structures called extracellular senile plaques and intracellular neurofibrillary tangles [3]. This leads to the loss of connections among nerve cells and ultimately degeneration of neurons. The utmost common early symptom of $\mathrm{AD}$ is the trouble in recalling short-term memory [4]. For example unable to recall names, or where they place their keys or disoriented even in familiar places. Alzheimer's is a progressive disease [5]. This means that as the disease loans, disease status is also advanced. As this occurs, more brain's areas are dented and consequently more symptoms appear. In the advance stages of $\mathrm{AD}$, symptoms can include difficulties with language, mood swings, loss of motivation, non-managing self-care and behavioral issues. There are some enduring questions on how $\mathrm{AD}$ patient are aware of their declining cognitive abilities, how they retain a sense of individuality or morality, or whether they can still connect with their friends or loved ones. Emerging developments in neuroscience have facilitated scientists to more specifically examine the brains of the $\mathrm{AD}$ patients, proposing that while dementia alters some features of consciousness, others are extraordinarily spared.

Researchers have started combining the fact that how the damage of some functions, however the conservation of other functions, changes consciousness in $\mathrm{AD}$. Gil et al. examined numerous features of self-consciousness (SC) in patients with probable mild or moderate $\mathrm{AD}$ [6]. In this study a marked association was reported between SC and dementia. The furthermost reported discrepancy in consciousness were awareness of cognitive insufficiencies, moral judgments then prospective memory and lowest disturbed features were awareness of identity as well as mental depiction of the body. In the Mini Mental State (MMS) score a significant correlation was found for anosognosia and moral judgments. Furthermore, irrespective of MMS score consciousness of identity was flawless. Anosognosia is the mostly reported discrepancy in consciousness. The patients with mild cognitive impairment (MCI) are usually aware of their memory deficit but $\mathrm{AD}$ patients may be uninformed. Kalbe et al. investigated the linkage of cognitive domains in patients with very mild $\mathrm{AD}$ and subjects with MCI [7]. In this study the self-report of cognitive troubles were compared for $\mathrm{AD}$ and MCI patients. The denouements suggested considerably more cognitive impairment for $\mathrm{AD}$ patients with respect to caregivers $\mathrm{MCI}$ patients. But AD patients complained significantly less cognitive dysfunctions. These aforementioned signs advocate that only several facets of consciousness and self-awareness are doubtlessly steal in $\mathrm{AD}$.

Alzheimer's pathology impedes with the creation of memories and it's one of the major symptoms. Memory deficits are linked with worsening of consciousness in dementia [8]. For example, AD patients cannot guess how they will remember episodic memory such as, indicating to a particular impairment in awareness of their personal memories, however, they can precisely predict how well they will recall semantic information in future. Lipinska et al. examined the recognition tests of general knowledge questions in both normal aging and patients in an early phase of $\mathrm{AD}$ [9]. The completions indicated intact monitoring of stored information in $\mathrm{AD}$ despite deficits in knowledge retrieval and relative independence between level of common knowledge and Feeling-of-Knowing (FOK) accuracy in normal aging and AD. Souchay et al. studied the role of episodic memory FOK in patients with $\mathrm{AD}$, elderly partakers and younger adults [10]. The consequences specified dementia-linked arrears on the recall and recognition tests. AD patients showed diminished FOK correctness with respect to elderly participants. This outcome specifies that early $\mathrm{AD}$ is connected with an insufficiency in episodic memory.

The medial temporal, lateral temporal, parietal and frontal lobes of the brain may engender consciousness by championing recall of memory, self-referential concoct and self-credentials. But in AD brain atrophy begins in the aforementioned zones [11]. For AD patients in temporal and parietal lobes, metabolism is abated that lead to alteration of consciousness. Moreover, it's audacious for AD patients to realize one's personality. The network connecting frontal, parietal and temporal lobes are compromised in $\mathrm{AD}$. In the initial stage of $\mathrm{AD}$, medial temporal lobe is primarily affected but at advanced stage total network effete. Medial temporal lobe is crucial in case of $\mathrm{AD}$ patients. It has been found that in the medial temporal lobe, the hippocampus binds background information about an experience into memory, nonetheless must communicate through the brain to stock these specifics into long-term memory. Consequently, disturbed sense of awareness might start along with the early damage to the medial temporal lobe.

Consciousness is the summation of sentience, access to information, as well as self-knowledge [12]. In case of AD patient's summation of sentience and access to information are relatively sound. Self-knowledge is strongly linked to episodic memories. Indicator of impaired consciousness in $\mathrm{AD}$ patients includes difficulty in remembering semantic information particularly personal experiences and these impairments are often seen along with the problems of episodic memory. Since dementia often alters an individual's sense of time perception, this temporal disconnect may perhaps additionally damage an individual's capacity to correctly place themself in the setting of past and future.

\section{Acknowledgements}

The author wishes to thank the anonymous reviewre(s)/ editors (s) of this article for their constructive reviews.

\section{Competing Interests}

The author states no competing interests.

*Corresponding author: Md. Sahab Uddin, Department of Pharmacy, Southeast University, Dhaka, Bangladesh, Tel: +880 1710220110; E-mail: msu-neuropharma@hotmail.com, msu_neuropharma@hotmail.com

Received September 05, 2017; Accepted September 11, 2017; Published September 14, 2017

Citation: Uddin MS (2017) Alzheimer's Disease and You: Can Alzheimer's Abduct Consciousness? J Neurol Disord 5: e123. doi:10.4172/2329-6895.1000e123

Copyright: ( 2017 Uddin MS. This is an open-access article distributed under the terms of the Creative Commons Attribution License, which permits unrestricted use, distribution, and reproduction in any medium, provided the original author and source are credited. 
Citation: Uddin MS (2017) Alzheimer's Disease and You: Can Alzheimer's Abduct Consciousness? J Neurol Disord 5: e123. doi:10.4172/2329$6895.1000 \mathrm{e} 123$

\section{References}

1. Uddin MS, Haque A, Mamun AA, Iqbal MA, Kabir MT (2016) Searching the linkage between high fat diet and Alzheimer's disease: A debatable proof stand for ketogenic diet to alleviate symptoms of Alzheimer's patient with APOE $\varepsilon 4$ allele. J Neurol Neurophysiol 7: 1-9.

2. Uddin MS, Asaduzzaman M, Mamun AA, Iqbal MA, Wahid F, et al. (2016) Neuroprotective activity of Asparagus racemosus Linn. against ethanolinduced cognitive impairment and oxidative stress in rat's brain: Auspicious for controlling the risk of alzheimer's disease. J Alzheim Dis Parkinsoni 6: 1-10.

3. Uddin MS, Mamun AA, Hossain MS, Akter F, Iqbal MA, et al. (2016) Exploring the effect of Phyllanthus emblica $L$. on cognitive performance, brain antioxidant markers and acetylcholinesterase activity in rats: Promising natural gift for the mitigation of Alzheimer's disease. Annal Neurosci 23: 218-229.

4. Uddin MS, Mamun AA, Hossain MS, Ashaduzzaman M, Noor MA, et al. (2016) Neuroprotective effect of Phyllanthus acidus L. on learning and memory impairment in scopolamine-induced animal model of dementia and oxidative stress: Natural wonder for regulating the development and progression of Alzheimer's Disease. Adv Alzheimer's Dis 5: 53-72.

5. Uddin MS, Mamun AA, Iqbal MA, Islam A, Hossain MF, et al. (2016) Analyzing nootropic effect of Phyllanthus reticulatus Poir. on cognitive functions, brain antioxidant enzymes and acetylcholinesterase activity against aluminiuminduced Alzheimer's model in rats: Applicable for controlling the risk factors of Alzheimer's disease. Adv Alzheimer's Dis 5: 87-102.
6. Gil R, Arroyo-Anllo EM, Ingrand P, Gil M, Neau JP, et al. (2001) Selfconsciouness and Alzheimer's disease. Acta Neurol Scand 104: 296-300.

7. Kalbe E, Salmon E, Perani D, Holthoff V, Sorbi S, et al. (2005) Anosognosia in very mild Alzheimer's disease but not in mild cognitive impairment. Dement Geriatr Cogn Disord 19: 349-356.

8. Uddin MS, Nasrullah M, Hossain MS, Rahman MM, Sarwar MS, et al. (2016) Evaluation of nootropic activity of Persicaria flaccidaon cognitive performance, brain antioxidant markers and acetylcholinesterase activity in rats: Implication for the management of Alzheimer's disease. American J Psychi Neuroscience 4: $26-37$.

9. Lipinksa B, Backman L (1996) Feeling-of-knowing in fact retrieval: Further evidence for preservation in early Alzheimer's disease. J Int Neurospcyh Soc 2: $350-358$.

10. Souchay C, Isingrini M, Gil R (2002) Alzheimer's disease and feeling-ofknowing in episodic memory. Neuropsycholo 40: 2386-2396.

11. Risacher SL, Shen L, West JD, Kim S, McDonald BC, et al. (2010) Longitudinal MRI atrophy biomarkers: Relationship to conversion in the ADNI cohort. Neurobio Agi 31: 1401-1418.

12. Laureys S (2005) The boundaries of consciousness: Neurobiology and neuropathology. Elsevier, NY, USA. 